\title{
Effecting Flow: The Relationship between the Perceived Team Climate for Innovations and the Experience of Flow and Worry
}

\author{
Laura Sophie Aichroth ${ }^{1,}$ Mandy Nuszbaum ${ }^{2}$, Laura Campoy Gomez ${ }^{3}$ \\ ${ }^{1}$ Universidad Católica San Antonio de Murcia (UCAM), Murcia, Spain \\ ${ }^{2}$ University of Applied Sciences (FOM), Muenster, Germany \\ ${ }^{3}$ Universidad Católica San Antonio de Murcia (UCAM), Murcia, Spain
}

\begin{abstract}
.
Over the past decades, the interest in research and practical recommendations on innovation climate at team and organizational level has grown. Furthermore, the positive effects of flow experience have become increasingly present at work. For the target group of members of product software development teams in Germany $(\mathrm{N}=323)$, this study identified a significantly positive relation between the perceived team climate for innovations and the individual flow experience, whereas there is no significant relation between the perceived team climate for innovations and the individual experience of worry. Gender has no moderating effect. Regarding the four dimensions of the team climate for innovations, the expression of vision is relatively low for the target group of product software development teams in Germany compared to the norm tables. Participative safety is comparably high and task orientation and support for innovations are moderately distinctive. This means, all dimensions, except participative safety, need interventions in order to strengthen the team climate for innovations itself and thereby foster the flow experience. Since the extent of experiencing both flow and worry is relatively high, software product development itself and respectively the work environments seem to be stimulating, but also concerning for team members, which is why these aspects need action.
\end{abstract}

Keywords: business psychology; environment; perception; products; software development 


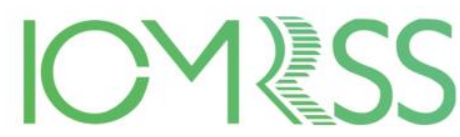

06-08 November, 2020

MUNICH, GERMANY

\section{Introduction}

The area of innovation is constantly growing. In the economic market, especially technological innovations are considered to have a positive effect on organizations (Heinze \& Heinze, 2020). The ability to be innovative is important when thriving to remain competitive and sustainably successful in the global economic competition. Furthermore, it is becoming crucial for organizations to be innovative in order to differentiate their own product and service offerings from those of their competitors and to provide added value to their own customers (Newman, Rang, Wang \& Mount, 2020). Thereby, organizations are dependent on multidisciplinary teams, since team work promotes individual participation, the willingness to make an effort, learning motivation, loyalty and creativity. Those effects are not only relevant for high performance, change and innovation, but also essential for the success of a team and the whole organization (Brodbeck, Anderson \& West, 2000, B). An understanding of innovation climate gives people in all roles of an organization the opportunity to make use of the levers to promote innovation within the organization (Newman et al., 2020). Research shows that the perceived team climate should be of interest to all group leaders, managers and organizations seeking a sustainable competitive advantage (Ramírez Heller, Berger \& Brodbeck, 2014). Amongst others, there is a relationship between the leadership style and the innovation atmosphere in an organization (Yongping Xie et al., 2018) and the innovation performance (Gerlach, Hundeling \& Rosing, 2020).

Although several workforce characteristics and outcomes on individual, team, leadership and organizational level have been examined, little research has been conducted on the relationship between the perceived team climate for innovations and the effects on flow or worry (Newman, 2020). For this reason, the current study expands previous knowledge by investigating this relationship. In general, flow is described as a state of mind that happens when someone feels optimally challenged and fully absorbed in the currently fulfilled activity. This state is perceived by the individual as engrossing and enjoyable (Csikszentmihalyi, 1999) and occurs more often at work than in leisure (Csikszentmihalyi \& LeFevre, 1989). In addition to the individual pleasant perception, a positive relation between the work-related flow experience and relevant outcomes for organizations has been shown (e. g. Eisenberger, Jones, Stinglhamber, Shanock \& Randall, 2005; Demerouti, 2006). In order to create a scientific contribution to the effects of the team climate for innovations, this study focuses on the connection between the team climate for innovations and the experience of flow and worry for software development teams in Germany. Therefore, the research question was whether there is a relation between the perceived team climate for innovations and the experience of flow and worry for software development companies in Germany. 


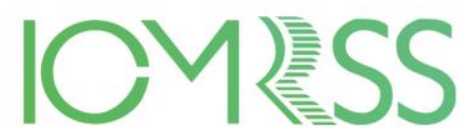

06-08 November, 2020

MUNICH, GERMANY

\subsection{Team climate for innovations}

Over the last two decades, the Team Climate Inventory for Innovations (TCI) by Brodbeck et al. (2000, B) has become one of the most important evaluation instruments to help understand the factors affecting the climate for innovations (Houston, Jackson \& Gilliotte, 2017). Hereby, innovation is defined as the "intentional introduction and application within a role, group or organization of ideas, processes, products or procedures, new to the relevant unit of adoption" (West, 1990). The TCI is a psychometric test to validate the atmosphere regarding innovations and effectivity in teams or work groups (Brodbeck et al., 2000, B). The understanding of the climate for innovations adopted in this study is consistent with the commonly used definition by Anderson and West (1998), who summarize it as the shared perception of the members of a team (or organization) on team (or organizational) level to what extent the experienced team (or organization) processes promote and enable innovation (Newman et al., 2020). The working group of interest was described as an either permanent or semi-permanent team to which individuals are associated and with whom they usually have interactions to fulfil work-related activities (Anderson \& West, 1998). The TCI was chosen, since one of its use cases is the evaluation of the team climate as a part of organizational development (Brodbeck et al., 2000, B). The construct team climate for innovations captures four sub-dimensions of innovation climate: vision, participative safety, task orientation and support for innovation. In addition, social desirability is measured and can be seen as a control variable (Anderson \& West, 1998).

\subsection{The experience of flow and worry}

It can be stated that optimal conditions benefit employees and organizations alike (e. g. Ilies et al., 2017; Kelloway et al., 2013). Employees who are motivated by the intrinsic aspects of their work tasks, want to continue their work and are fascinated by the tasks they perform (Bakker, 2008). In addition, it is not necessarily decisive what we do, but how we do it, to experience flow and thus joy in our work (Csikszentmihalyi, 1999). The flow experience is affected by multiple parameters and is positively related to several outcomes for individuals and organizations like a positive affect or job satisfaction (Illies et al., 2017). For the target group of software professionals $(\mathrm{N}=121)$ it has been shown that an individual's relative dayspecific state of being recovered at the beginning of a working day is positively related to the day-level flow experiences during work. Nevertheless, it did not reach a significant level $(\mathrm{r}=.40)$ to be set as a moderating variable (Debus, Sonnentag \& Nussbeck, 2014). Positive individual effects of experiencing flow also have positive consequences for organizations (Eisenberger et al., 2005). More experience of flow is significantly related to greater creativity, which is related positively to developing new or useful ideas or products. Although the direct relationship between curiosity and creativity did not reach statistical significance, flow positively connected curiosity with creativity (Schutte \& Malouff, 2020). In sum, the first hypothesis states:

Hypothesis 1: For members of software development teams in Germany, there is a positive relationship between the perceived team climate for innovations and the experience of flow.

When skills and requirements of an individual and the context of the situation match, not only flow but also worry is triggered. The aspect of worry is necessary to understand the 
consequences of flow triggering challenging conditions (Klauer, Stiensmeier \& Rheinberg, 2004). Furthermore, high skill and challenge are positively related to the individual performance and partially mediated by positive mood (Eisenberger et al., 2005). Therefore, individual coping strategies are essential to support the problem-oriented accomplishment of work requirements. In addition, the ability of coping is also positively related to affect and goal attainment (Daniels \& Harris, 2005). As creating innovations in forms of ideas and products is a challenging task, which needs curiosity and creativity (Schutte \& Malouff, 2020), it is reasonable to assume that worry may be triggered as well. Hence, the second hypothesis states:

Hypothesis 2: For members of software development teams in Germany, there is a negative relationship between the perceived team climate for innovations and the experience of worry.

\section{Methods}

\subsection{Sample and Procedure}

The study was conducted with developers, agile coaches, Scrum masters, user experience (UX) designers as well as project leads / project managers, (team) assistants and leadership roles, all working in the area of software product development. The questionnaire was answered online by all participants, which allowed an easy and fast evaluation of the data. All questions were fixed response questions. The survey technique used was an online survey. The online link was spread by networks, social media communities as well as within members of IT teams. The participation was voluntary, without any incentives and anonymous and the data was treated confidentially. The pretest of the study took place in April $2020(\mathrm{~N}=10)$, face-to-face as well as online-based. The participants of the pretest were not all part of the target group, since the focus also was on the correct spelling, grammar, understandability and duration of the test. The study took place in May and June 2020 therefore, the time period of the study was 2 months.

Using psychological tests, errors due to the test itself, the test application and the test person were aspired to be avoided in order to meet the demands regarding test quality (Newton \& Shaw, 2013). Errors due to the test itself were aimed to be avoided by contacting the authors of the tests before starting the study to get the approval for using the scales and making sure to use the current set of items and norm tables. In order to prevent mistakes caused by the test application, test execution information in the manuals were considered. For eliminating errors created by the test persons, the data sets were examined with respect to certain criteria: After cleaning the data and deleting the completed data sets with test persons not working in a team, sets with a suspicious duration of participation and outliner sets, the total number of used questionnaires for the data analysis was $\mathrm{N}=323$.

Data were collected by a multidimensional test. All items, including the socio-demographic data, have been mandatory. Among the 323 test persons included in the final analysis, $40.18 \%$ were female. Participants' age ranged from 20 years to 62 years $(M=34.90, S D=10.00)$. The team size ranged from two team members to 30 team members $(M=9.32, S D=5.40)$. Most represented roles were developers $(22.60 \%)$, (team) assistants $(15.17 \%)$ and project leads / project managers $(11.15 \%)$. Most participants worked in large companies with 201 or more 


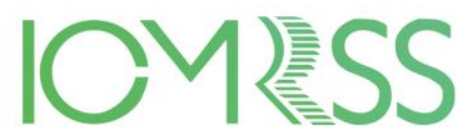

06-08 November, 2020

MUNICH, GERMANY

employees (54.49\%). The product areas most represented were software $(28.48 \%)$, online applications and online media (23.53\%) and service providers $(20.12 \%)$. The most used working methods were Scrum in an adapted form (30.96\%), classic project management (14.86\%) and checklists (13.62\%), followed by Kanban in an adapted form (13.00\%).

\subsection{Measures}

In order to gain insights on the perceived team climate for innovations and the experience of flow and worry, a multidimensional test was set up, containing two existing psychometric tests used by permission of the authors to operationalize the constructs.

\subsubsection{Team climate for innovations}

The team climate for innovations was measured by the Team Climate Inventory (TCI) for Innovations by Anderson and West (1998). The first factor, vision, refers to the concept of an estimated result, which represents a motivating strength at work and a higher order goal. The second factor, participative safety stands for an environment, that is felt as interpersonally not intimidating and actively promoting interactivity and participation in decision-making. The third, task orientation, refers to a common concern for the highest performance in fulfilment of tasks and the accountability of individuals and teams. Finally, support for innovation includes expectations, support and approval of efforts to initiating new and improved procedures. Applying this four-factor model (West, 1990), the 44-item TCI by Anderson and West (1998) was used, which also includes a six-item scale for social desirability. For the four subscales, consisting of 13 further subscales, a variety of response scales are used to examine the different aspects of the climate and effectivity (Brodbeck et al., 2000, B). For the items of the subscale vision the participants are asked to which extent each statement is true for their perception of their team. A seven-point scale is used ranging from $1=$ not at all to $7=$ completely. For participative safety responses are given on a five-point scale ranging from $1=$ strongly disagree $/$ very little extent to $5=$ strongly agree $/$ very great extent. For task orientation a seven-point response scale respectively a five-point response scale is used, from $1=$ to a very little extent to $7=$ to a very great extent and from $1=$ strongly disagree to $5=$ strongly agree, respectively. Regarding support for innovations, participants indicate the extent to which each statement given was true to their perception of their team on a five-point scale ranging from $1=$ strongly disagree to $5=$ strongly agree (Anderson \& West, 1998). Example items are "How clear are you about what your team objectives are?", "We all influence each other" or "People in the team co-operate in order to help develop and apply new ideas".

The TCI was used in a pre-version (Anderson, Brodbeck \& West, 2000, A) with the courtesy of the author Brodbeck. The TCI is available as a German standardized questionnaire. The construct of the pre-version has been selected, since it is operationalized by a highly standardized, validated scale of TCI dimensions with an average Cronbach's alpha of .86 (range: $\alpha=.84-.89$ ). The questionnaire started with the TCI. In order to validate the scales, one of the five scales was used with 2 items less to investigate whether the scale reliability changes. Therefore, 42 out of the 44 items of the pre-version of the TCI were used. Overall, Cronbach's alpha for the team climate for innovations was .96. Therefore, the TCI is reliable for members of software product development teams in Germany. In addition, previous work 


\section{3rd International Conference on Modern Research in}

SOCIAL SCIENCES

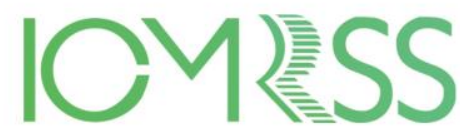

06-08 November, 2020

MUNICH, GERMANY

generally indicates that the TCI shows a high degree of reliability and convergent validity (Mathiesen \& Einarsen, 2004; Anderson \& West, 1996). For this reason, the validity was not tested again within this study.

\subsubsection{Flow and worry}

The flow experience was evaluated by the Flow Short Scale (FSS) by Rheinberg, Vollmeyer and Engeser (2019). The TCI scales were followed by the FSS with 13 items, including 10 items for the subscale flow and three items for the subscale worry. The order of the two scales was selected this way, since the items within the TCI are more precisely answerable than the FSS, in order to prevent frustration for the participants. The order of the items within the study was determined by the order within the two standardized psychometric tests, which were combined in one new test with the authorization of the authors. The FSS was used with the courtesy of the author Rheinberg and in compliance with the Creative Commons conditions. The FSS is available in a German standardized questionnaire (Rheinberg et al., 2019). The construct is operationalized by a highly standardized, validated scale $(\alpha=.90)$ (Klauer et al., 2004). All items were answered on a seven-point Likert scale, ranging from $1=$ not true at all to $7=$ very true. The participants were instructed to report their experience at work. Sample items for flow were "I feel just the right amount of challenge" and "I am totally absorbed in what I am doing". For worry example items are "I won't make any mistake here" and "I am worried about failing" (Rheinberg et al., 2019). Overall, for the subscale of flow Cronbach's alpha was .84 and ranged over all items if an item dropped from .81 to .85 . For the subscale of worry, Cronbach's alpha was .73 and ranged over all items if an item dropped from .54 to .75. Therefore, the FSS is reliable for members of software product development teams in Germany. Prior research also found the FSS to be reliable and valid (Kryazos et al., 2008). Since the participants were working in Germany and both scales, the TCI and FSS are, as stated, available in a German validated version, the questionnaire was conducted in German.

\subsection{Control Variables and prerequisites}

In order to control the data, the sub-scale social desirability of the TCI was considered. Comparing the results of the study to the norm tables of Brodbeck et al. (2000, B), the results show that for members of software development teams in Germany, social desirability is recognizable to a certain extent $(M=3.41, S D=0.04$, sum scale value of 20.44 , see Table 1$)$. Therefore, tests of the prerequisites were made to a special degree in order to ensure methodical quality. The Durbin-Watson statistics for autocorrelation showed, that there are no first-degree autocorrelations effects, so the residuals do not correlate, which can be seen for the model of the team climate for innovations and flow and worry in Table 2.

The variance inflation factor (VIF) showed, that multi-collinearity does not exist $(<10)$. Due to the sample size of $\mathrm{N}=323$, the results were bootstrapped to avoid the residual plot showing the residuals vs. predicted displaying heteroscedasticity of the residuals and to strengthen the homoscedasticity assumption of the residuals, which can be seen in Figure 1. Bootstrapping was based on 5000 replicates. 


\section{3rd International Conference on Modern Research in}

SOCIAL SCIENCES

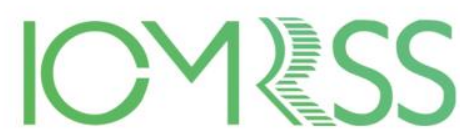

06-08 November, 2020

MUNICH, GERMANY

Figure 1: Residuals vs. predicted values, standardized residuals histograms and $Q-Q$ plots for standardized residuals for the perceived team climate for innovations and flow and worry

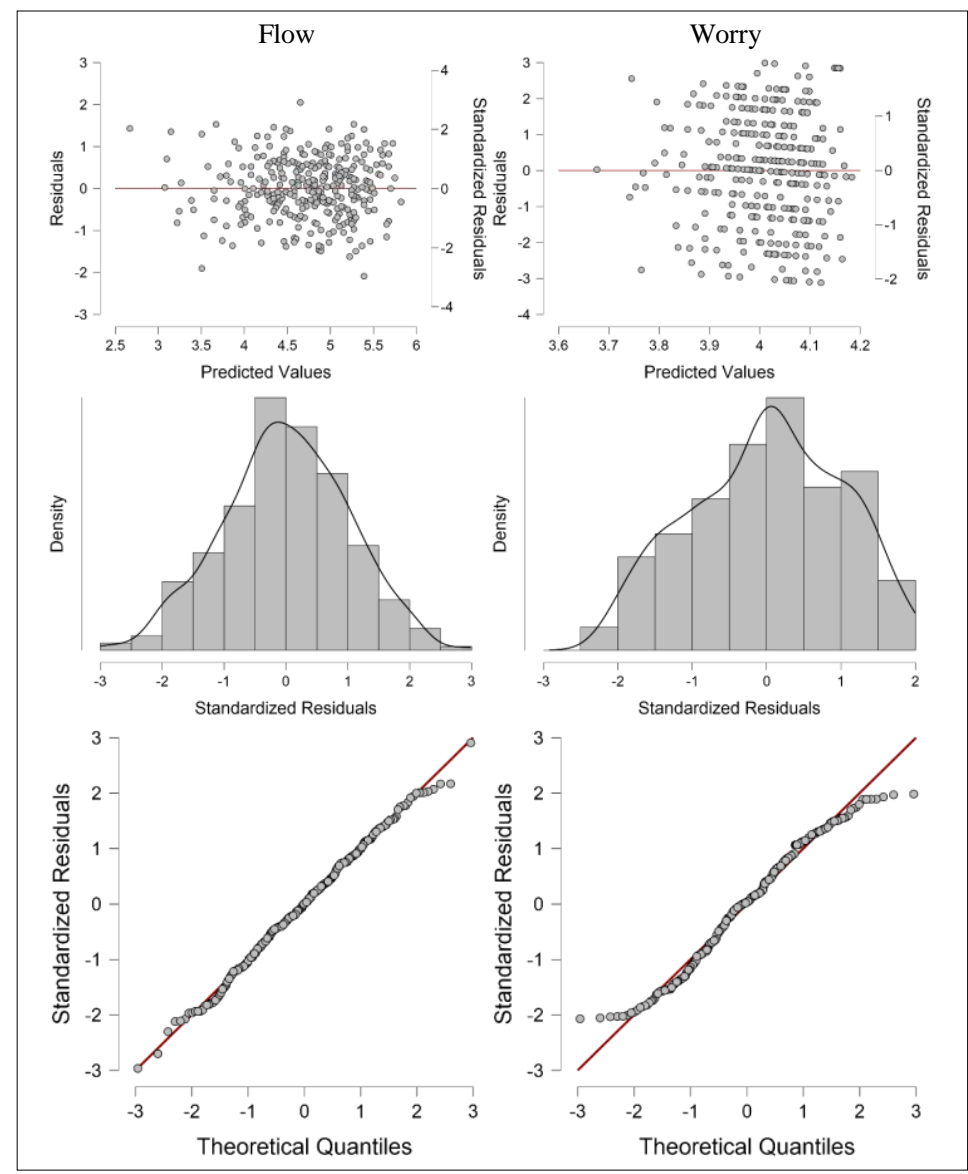

As displayed in figure 1, in the scatter plot you can see that the values bounce randomly and thereby form a roughly horizontal band around the residual line. Little data points stand out from the basic random pattern of the other residuals. In addition, the histogram strengthens the appearance. For significance testing of normal distribution with the chosen alpha level of .05 , the p-values of the Shapiro Wilk test (Table 1) show that the p-values for the TCI $(\mathrm{p}<.001)$, flow $(\mathrm{p}=0.185)$ and worry $(\mathrm{p}<.001)$ are greater than .05 , so the null hypothesis, that the data are normally distributed, is not rejected. In addition, the Q-Q plot shows that the data points for both models are very close to or even on the linear path.

For the TCI, the reference measures and norm tables of the target group of members of product and software development teams were used (Brodbeck et al. 2000, B). For the FSS the comparative key figures and norm tables were used (Rheinberg et al., 2019). 


\section{Results}

\subsection{Descriptive statistics}

Means, standard deviations, medians, minimums and maximums are displayed in Table 1. The descriptive statistics of the TCI include the sum scale values of all subscales and the relating stanines in order to relate to the norm tables (Brodbeck et al., 2000, B).

Table 1: Descriptive statistics for TCI, flow and worry

\begin{tabular}{|l|l|l|l|l|l|l|l|l|}
\hline & Valid & Missing & $M$ & $S D$ & $\begin{array}{l}\text { Shapiro- } \\
\text { Wilk }\end{array}$ & $\begin{array}{l}\text { P-value of } \\
\text { Shapiro-Wilk }\end{array}$ & $\begin{array}{l}\text { Sum scale } \\
\text { value }\end{array}$ & Stanine \\
\hline Vision & 323 & 0 & 3.75 & 0.03 & 0.97 & $<.001$ & 33.74 & 2 \\
\hline Participative safety & 323 & 0 & 4.12 & 0.03 & 0.95 & $<.001$ & 49.34 & 7 \\
\hline Task orientation & 323 & 0 & 3.84 & 0.04 & 0.95 & $<.001$ & 26.88 & 6 \\
\hline Support for innovations & 323 & 0 & 3.78 & 0.04 & 0.97 & $<.001$ & 30.15 & 6 \\
\hline Social desirability & 323 & 0 & 3.41 & 0.04 & 0.98 & $<.001$ & 20.44 & - \\
\hline TCI (overall) & 323 & 0 & 3.82 & 0.03 & 0.97 & $<.001$ & - & - \\
\hline Flow & 323 & 0 & 4.74 & 0.05 & 0.99 & 0.185 & - & - \\
\hline Worry & 323 & 0 & 4.01 & 0.08 & 0.98 & $<.001$ & - & - \\
\hline
\end{tabular}

Comparing the results of the study to the norm tables for product and software development teams of Brodbeck et al. (2000, B), the results of the current study show that for members of software development teams in Germany, the dimension vision is relatively low (stanine range 1,2,3), below average. Participative safety is comparably high (stanine range 7, 8, 9). Task orientation and support for innovations are average (stanine range $4,5,6)$. The extent of the experience of flow $(M=4.76, S D=0.05)$ and worry $(M=4.01, S D=0.08)$, both are relatively high (Rheinberg et al., 2019).

\subsection{Hypotheses testing}

Table 2 shows the results of the regression analysis used to test the hypotheses, the relation between the team climate of innovations and flow and worry. For both models, the p-values are $>.05$, which indicates a positive directional relation.

Table 2: Model Summary - Flow and worry

\begin{tabular}{|c|c|c|c|c|c|c|c|c|c|c|c|c|c|}
\hline & \multirow{3}{*}{\begin{tabular}{|l}
$\mathrm{R}$ \\
.000 \\
\end{tabular}} & \multirow{3}{*}{$\begin{array}{l}\mathrm{R}^{2} \\
.000 \\
\end{array}$} & \multirow{3}{*}{$\begin{array}{l}\text { Adjusted } \\
\mathrm{R}^{2} \\
.000 \\
\end{array}$} & \multirow{3}{*}{$\begin{array}{l}\text { RMSE } \\
0.902 \\
\end{array}$} & \multirow{3}{*}{$\begin{array}{l}\mathrm{R}^{2} \\
\text { Change } \\
.000\end{array}$} & \multirow[b]{2}{*}{$\begin{array}{l}\mathrm{F} \\
\text { Change }\end{array}$} & \multirow{3}{*}{$\begin{array}{l}\text { df1 } \\
0 \\
\end{array}$} & \multirow{3}{*}{\begin{tabular}{|l|} 
df2 \\
322 \\
\end{tabular}} & \multirow[b]{2}{*}{$\mathrm{p}$} & \multicolumn{3}{|c|}{ Durbin-Watson } \\
\hline & & & & & & & & & & & \begin{tabular}{|l|} 
Auto- \\
correlat \\
ion \\
\end{tabular} & Statistic & $\mathrm{p}$ \\
\hline \multirow[b]{2}{*}{$\frac{3}{2}$} & $\mathrm{H}_{0}$ & & & & & & & & & & -0.010 & 2.017 & .879 \\
\hline & $\mathrm{H}_{1}$ & .624 & .389 & .388 & 0.706 & .389 & 204.769 & 1 & 321 & $<.001$ & 0.049 & 1.901 & .369 \\
\hline \multirow[b]{2}{*}{$\begin{array}{l}\overrightarrow{0} \\
3 \\
3\end{array}$} & $\mathrm{H}_{0}$ & .000 & .000 & .000 & 1.511 & .000 & & 0 & 322 & & -0.036 & 2.070 & .529 \\
\hline & $\mathrm{H}_{1}$ & .060 & .004 & .000 & 1.510 & .004 & 1.158 & 1 & 321 & 0.283 & -0.030 & 2.056 & .613 \\
\hline
\end{tabular}

Hypothesis 1: For members of software development teams in Germany, there is a positive relationship between the perceived team climate for innovations and the experience of flow. 
The bivariate correlation coefficient for flow $\mathrm{p}<.001$ indicates a positive correlation between the perceived team climate for innovations and flow regarding the population of members of software product development teams. In addition, with the characteristic sample value $r=.624$, it can be stated that there is a significant positive correlation between the perceived team climate for innovations and flow. In this case, a bivariate correlation exists, so the correlation coefficient will be directly considered as standardized effect size measure. With a value of $\mathrm{r}>.5$, there is a strong effect (Cohen, 1988). Figure 2 also shows the partial regression plots for testing hypothesis 1 with the relation between the perceived team climate for innovations and flow.

Figure 2: Partial regression plot for team climate for innovations and flow, respectively worry

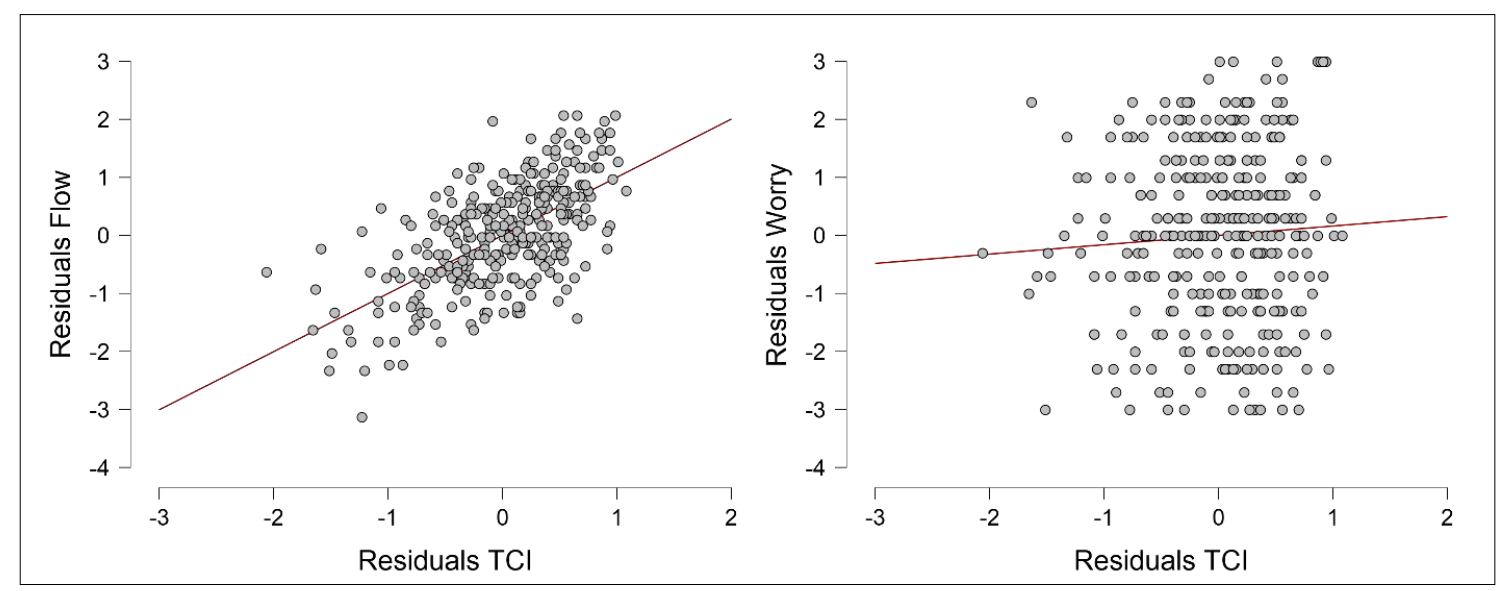

In addition to the numbers before, in Figure 2, the partial regression plot shows the linear dependency between the covariate team climate for innovations and the dependant variable flow. The $\mathrm{R}^{2}$-value in Table 2 indicates that team climate for innovations is a suitable covariate to explain flow as a dependent variable with $38.9 \%$ of the variation within the model. The adjusted $\mathrm{R}^{2}$ did not improve, which means that the fit of the model regarding the data needs to be seen critically.

Pearson's correlation showed a significant correlation between the perceived team climate for innovations and the experience of flow $(\mathrm{r}=.624, \mathrm{p}>.05)$, the perceived team climate for innovations accounts for $38.9 \%$ of the variance the flow experience, which leads to accept hypothesis 1 . There is a positive relation between the perceived team climate for innovations and the flow experience for members of software product development teams in Germany.

Hypothesis 2: For members of software development teams in Germany, there is a negative relationship between the perceived team climate for innovations and the experience of worry.

Regarding the bivariate correlation coefficient for worry with $p=0.283$, there is a positive correlation between the perceived team climate for innovations and worry regarding the population of members of software product development teams. In addition, with the characteristic sample value $r=.060$ (Table 2), it can be stated that there is almost no correlation between the perceived team climate for innovations and worry. Since a bivariate correlation exists, the correlation coefficient will be directly considered as standardized effect size measure. With a value of $r<.1$, there is no effect (Cohen, 1988). Additionally, Figure 2 
shows the partial regression plots for testing hypothesis 2 , which indicates that there is almost no dependency between the covariate team climate for innovations and the dependent variable worry. The $\mathrm{R}^{2}$-value in Table 2 supports that team climate for innovations is not suitable to explain worry as a dependent variable with $4 \%$ of the variation within the model. The adjusted $\mathrm{R}^{2}$ did not improve, which means that the fit of the model regarding the data needs to be seen critically.

Pearson's correlation showed a slightly positive, but no significant correlation between the perceived team climate for innovations and the experience of worry $(r=.060, p>.05)$, the perceived team climate for innovations accounts for $4 \%$ of the variance of the experience of worry, which leads to reject hypothesis 2 . There is no relation between the perceived team climate for innovations and the worry experience for members of software product development teams in Germany.

In order to avoid gender effects, a moderation was examined, which is displayed in Table 3.

Table 3: Coefficients of testing gender effects

\begin{tabular}{|l|l|l|l|l|l|l|}
\hline \multicolumn{2}{|l|}{ Model } & Unstandardized & $\begin{array}{l}\text { Standard } \\
\text { Error }\end{array}$ & Standardized & $\mathrm{t}$ & $\mathrm{p}$ \\
\hline \multirow{3}{*}{$\mathrm{H}$} & $($ Intercept $)$ & 1.118 & 0.300 & & 3.725 & $<.001$ \\
\cline { 2 - 7 } 0 & TCI & 1.000 & 0.070 & 0.623 & 14.317 & $<.001$ \\
\cline { 2 - 7 } & Gender & -0.130 & 0.080 & -0.071 & -1.632 & 0.104 \\
\hline \multirow{3}{*}{$\mathrm{H}$} & (Intercept) & 0.997 & 0.906 & & 1.100 & 0.272 \\
\cline { 2 - 7 } & TCI & 1.032 & 0.234 & 0.643 & 4.412 & $<.001$ \\
\cline { 2 - 7 } & Gender & -0.053 & 0.548 & -0.029 & -0.097 & 0.923 \\
\cline { 2 - 8 } & TCIxGender & -0.020 & 0.142 & -0.046 & -0.142 & 0.887 \\
\hline
\end{tabular}

Gender was evaluated as a dichotomous moderator. For the H1 Model (Table 3), it can be stated, that there is no significant interaction effect of the perceived team climate for innovations on flow, which means it is not moderated by gender.

\section{Discussion}

In order to make use of team work that contributes to an organizational success, individuals need to be able to collaborate constructively and productively. As a prerequisite, a special atmosphere for innovation and team effectivity is needed (Brodbeck et al., 2000, B). Although, there is research evidence and common knowledge about the increasing importance for successful companies to define vision, mission and corporate values, it seems to have not yet become common practice to have such (Bratianu \& Balanescu, 2008). With regards to Brodbeck et al. (2000, B), the low level of the perceived vision shows that the members of software product development teams in Germany lack a clear, achievable, socially shared vision and associated goals that are valued by all. Intense and structured interventions are needed. Having a shared vision, helps to communicate internally and externally the existential goal of the company (Bratianu \& Balanescu, 2008). It is important to have a psychologically safe environment, especially for software development organizations (Thorgen \& Caiman, 2019). Regarding participative safety, the team climate for the target group is solid. It can be assumed that teams meet regularly and/or all members take part in the decision-making 


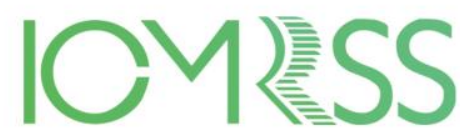

06-08 November, 2020

MUNICH, GERMANY

process. In addition, team members feel secure when submitting new ideas to the team. They trust each other and contribute fully to the achievement of the team goals and vision (Brodbeck et al., 2000, B), which presupposes that these are available. There is room for improvement concerning task orientation and the support for innovations. There is a wide range of recommended software development and quality assurance practices (Ghanbari, Vartiainen \& Siponen, 2018). When it comes to task orientation, team members basically stand behind the goals of excellent performance standards. Sometimes the own work is viewed critically or constructively, and help for the further development of new ideas is basically available. Regarding the support for innovations, there is some support for innovation, but willingness and active support could be improved. There is some innovation to a certain extent, but the usual is preferred. More resources could be used for innovation (Brodbeck et al., 2000, B). In terms of social desirability, the target group shows an average tendency of response behavior. A certain glossing over of the social and / or task climate is discernible (Brodbeck et al., 2000, B). The tendency of socially desirable answers can be seen as critical under the aspect that organizational research has identified psychological security as a critical factor for understanding phenomena such as voice or teamwork (Edmondson \& Lei, 2014).

As the results of the linear regression analysis show, the significantly positive relation between the perceived team climate for innovation and the flow experience expands previous knowledge on workforce characteristics and outcomes on individual, team, leadership and organizational level (Newman et al., 2020). The likelihood of a positive correlation between challenge and workload (Ilies et al., 2017) also supports the assumption of a liberated approach in handling challenges as a characteristic of an organizational culture supporting innovativeness and decisiveness (Heinze \& Heinze, 2020). The extent of experiencing flow for members of software product development teams in Germany is high compared to the reference measures (Rheinberg et al., 2019), which can be seen as an asset for those organizations. Furthermore, workplace changes not only satisfy employees' needs for competence and autonomy, which leads to greater satisfaction and positive effects on the workplace, but also promote the experience of flow. Therefore, organizations could not only improve the well-being of employees by enabling them to design their workplaces in a way that facilitates the flow of work but also supports innovations (Illies et al., 2017), which is another potential driver for organizations to remain sustainably innovative, successful and competitive.

Although there is no significant correlation between the perceived team climate for innovations and the experience of worry, the high extent of experiencing worry for software product development teams in Germany (Rheinberg et al., 2019) can be seen as an indicator that either the consequences of flow triggering challenging conditions are perceived to be too uncertain (Klauer, Stiensmeier \& Rheinberg, 2004) or that the culture does not support the feeling of being psychologically safe. This shows that these organizations underestimate the human need to feel safe at work, which is a prerequisite for growing, learning, contributing and working effectively in a rapidly changing world. Team members must feel safe so that they are willing to offer ideas, admit mistakes, ask for help or even give feedback in the hierarchy of the organization (Edmondson \& Lei, 2014). Therefore, it needs further 
examinations to understand why there is no or even no negative relation between the perceived team climate for innovations and experiencing worry.

\subsection{Managerial implications}

All activities with regards to supporting innovations start with providing support and articulating a vision by the leadership. In addition, there is a necessity for managers to encourage the members of their teams to be reflexive, ambitious and motivate one another (Newman et al., 2020). This can be a particular challenge for the growing number of organizations that are looking for ways to be less hierarchical, more innovative, more agile and more enriching for employees (Lee \& Edmondson, 2017). In order to strengthen the assumption that a liberated approach in handling challenges is characteristic for an organizational culture supporting innovativeness and decisiveness (Heinze \& Heinze, 2020), managers also find it helpful to develop a climate of innovation within the team to design team tasks that are complex and challenging (Newman et al. 2020), which needs managerial attention and action. In addition, managers should focus on actions and their behavior supporting team members to feel safe so that they are willing to offer ideas, admit mistakes, ask for help or even give feedback in the hierarchy of the organization (Edmondson \& Lei, 2014). Further research should examine the appropriate leadership style for the target group.

\subsection{Limitations and directions for future research}

The target group showed social desirability to a certain extent. This can be seen as critical with regards to the credibility of the answers given in the part of the TCI, but also with regards to all answers. Due to the arrangement of the scales, there may be sequential effects. These are averaged out if an effect exists because the order was identical for all participants. However, the survey should again be randomized for verification. In addition, in order to avoid a sampling error, the study should be replicated to review whether the sample selection maps the population relations. Furthermore, due to the values for $\mathrm{R}^{2}$, a systematic prognosis based on this model should be verified. The test validity for the FSS (Kryazos et al., 2018) is given for other cultural contexts but not enough for the German one and the target group of interest. Although prior work generally indicates that the TCI shows a high degree of reliability and convergent validity (Mathiesen \& Einarsen, 2004; Anderson \& West, 1996), this should be examined for the chosen target group. Those are further critical aspects with regards to the scientific quality of this study.

Since the manners in the area of software product development are based on the German informal personal address, the questionnaires were adapted in the salutation, and spelling mistakes in the scales were corrected. These adaptations can also lead to distortions. Due to the wide range of team size from two team members to 30 team members, the research should be revised with different team sizes to examine whether there are group differences and effects. Further group differences should be investigated concerning the working method, company size or the structuring of high or low hierarchy levels. In order to strengthen the knowledge with regards to core product software development roles, a repetition with software developers, UX designers and Scrum masters or agile coaches should be conducted. 
Due to the importance of psychological safety for developing a climate for innovations on the one hand and fostering the experience of flow and the avoidance of worry on the other hand, further research should evaluate the extent of psychological safety for the target group of software product development teams in Germany. Furthermore, it should be examined, which kind of leadership style promotes the existence of psychological safety.

\section{Conclusion}

Making use of the significant correlation between the perceived team climate for innovations and the experience of flow, it should be focused and strengthened as part of organizational development (Brodbeck et al., 2000, B), since more experience of flow is significantly related to greater creativity, which is related positively to developing new or useful ideas or products (Schutte \& Malouff, 2020). Because of the relationship between the leadership style and the innovation atmosphere in an organization (Yongping Xie et al., 2018) and the innovation performance (Gerlach, Hundeling \& Rosing, 2020), especially group leaders and managers should be supported by suitable actions to make use of the sustainable competitive advantage (Ramírez Heller, Berger \& Brodbeck, 2014) of having a flourishing innovation climate. Although no relation between the perceived team climate for innovations and the experience of worry could be examined in this study, the extent of experiencing worry in general is characteristically high for members of software product development teams in Germany. Therefore, supporting the development of individual coping strategies is essential to support the problem-oriented accomplishment of work requirements (Daniels \& Harris, 2005).

In general, regarding the four dimensions of the team climate for innovations, the expression of vision is relatively low for the target group compared to the norm tables, which indicates a strong need of action for software product development organizations in Germany in order to make use of the positive effects of having clear orientation by having a strong and shared vision. Participative safety is comparably high and task orientation and support for innovations are moderately distinctive. This means, all dimensions, except participative safety, need organizational and leadership interventions in order to strengthen the team climate for innovations itself and thereby support the flow experience of their employees and make use of the known organizational advantages of this effect.

\section{Acknowledgement}

This paper is an output of the science project as a cooperation between the UCAM and FOM, examining variables with regards to the organizational resilience for the target group of software product development companies in Germany. We thank Prof. Dr. Felix C. Brodbeck and Prof. Dr. Falko Rheinberg for the courtesy of using the scales. In addition, we thank Prof. Dr. Falko Rheinberg for all the supportive information. 


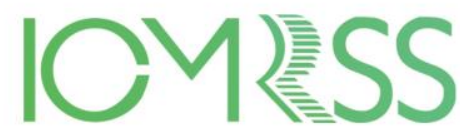

06-08 November, 2020

MUNICH, GERMANY

\section{References}

Anderson, N. \& West, M. A. (1996). The team climate inventory: Development of the TCI and its applications in teambuilding for innovativeness. European Journal of Work and Organizational Psychology, 5(1), pp. 53-66. https://doi.org/10.1080/13594329608414840.

Anderson, N. R. \& West, M. A. (1998). Measuring climate for work group innovation: development and validation of the team climate inventory. Journal of Organizational Behavior, 19(3), 235258.

Bakker, A. B. (2008). The work-related flow inventory: Construction and initial validation of the WOLF. Journal of Vocational Behavior, 72(3), pp. 400-414. https://doi.org/10.1016/j.jvb.2007.11.007.

Bratianu, C. \& Balanescu, G. V. (2008). Vision, mission and corporate values: A comparative analysis of the top 50 US companies. Management \& Marketing, 3(3), pp. 19-38.

Brodbeck, F. C., Anderson, N. \& West, M. A. (2000, A). Das Teamklima-Inventar: Handanweisung. [The Team Climate Inventory: Manual]. WOP Working Paper No. 2000 / 2.

Available: http://www.psy.lmu.de/wirtschaftspsychologie_en/forschung/working_paper/wop_workin g_paper_2000_2.pdf.

Brodbeck, F. C., Anderson, N. \& West, M. A. (2000, B). Das Teamklima-Inventar: Handanweisung und Validierung der deutschsprachigen Version [The Team Climate Inventory: Manual and validation of the German version]. Heidelberg: Hogrefe.

Cohen, J. (1988). Statistical Power Analysis for the Behavioral Sciences (2nd ed.). New York: Erlbaum.

Csikszentmihalyi, M. (1999). If we are so rich, why aren't we happy? American Psychologist, 54(10), pp. 821-827. doi:10.1037/0003066X.54.10.821.

Csikszentmihalyi, M. \& LeFevre, J. (1989). Optimal experience in work and leisure. Journal of Personality and Social Psychology, 56(5), pp. 815-822. https://doi.org/10.1037/00223514.56.5.815.

Daniels, K., \& Harris, C. (2005). A daily diary study of coping in the context of the job demands-control-support model. Journal of Vocational Behavior, 66(2), pp. 219-237. https://doi.org/10.1016/j.jvb.2004.10.004.

Debus, M. E., Sonnentag, S., Deutsch, W. \& Nussbeck, F. W. (2014). Making flow happen: The effects of being recovered on workrelated flow between and within days. Journal of Applied Psychology, 99(4), pp. 713-722. https://doi.org/10.1037/a0035881.

Demerouti, E. (2006). Job characteristics, flow, and performance: The moderating role of conscientiousness. Journal of Occupational Health Psychology, 11(3), pp. 266-280. https://doi.org/10.1037/10768998.11.3.266.

Edmondson, A. C. \& Lei, Z. (2014). Psychological Safety: The History, Renaissance, and Future of an Interpersonal Construct. Annual Review of Organizational Psychology and 


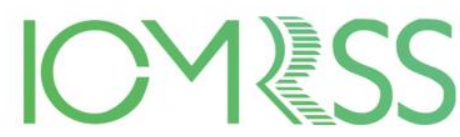

06-08 November, 2020

MUNICH, GERMANY

Organizational Behavior, 1(1), pp. 23-43. https://doi.org/10.1146/annurev-orgpsych031413-091305.

Eisenberger, R., Jones, J. R., Stinglhamber, F., Shanock, L. \& Randall, A. T. (2005). Flow experiences at work: for high need achievers alone? Journal of Organizational Behavior, 26(7), pp. 755-775. https://doi.org/10.1002/job.337.

Gerlach, F., Hundeling, M. \& Rosing, K. (2020). Ambidextrous leadership and innovation performance: a longitudinal study. Leadership \& Organization Development Journal, 41(3), pp. 383-398. https://doi.org/10.1108/LODJ-07-2019-0321.

Ghanbari, H., Vartiainen, T. \& Siponen, M. (2018). Omission of Quality Software Development Practices. ACM Computing Surveys, 51(2), pp. 1-27. https://doi.org/10.1145/3177746.

Heinze, K. L. \& Heinze, J. E. (2020). Individual innovation adoption and the role of organizational culture. Review of Managerial Science, 14(3), pp. 561-586. https://doi.org/10.1007/s11846-018-0300-5..

Houston, J. M., Jackson, C. A. \& Gilliotte, P. M. (2017). Team Climate Inventory (TCI). In V. Zeigler-Hill \& T. K. Shackelford (Eds.), Encyclopedia of Personality and Individual Differences, pp. 1-3. Springer International Publishing. https://doi.org/10.1007/978-3-31928099-8_90-1.

Ilies, R., Wagner, D., Wilson, K., Ceja, L., Johnson, M., DeRue, S. \& Ilgen, D. (2017). Flow at Work and Basic Psychological Needs: Effects on Well-Being. Applied Psychology, 66(1), pp. 3-24. https://doi.org/10.1111/apps.12075.

Kelloway, E. K., Weigand, H., McKee, M. C. \& Das, H. (2013). Positive Leadership and Employee Well-Being. Journal of Leadership \& Organizational Studies, 20(1), pp. 107117. https://doi.org/10.1177/1548051812465892.

Klauer, K., Stiensmeier, J. \& Rheinberg, F. (2004). Diagnostik von Motivation und Selbstkonzept. Zeitschrift Fuer Padagogische Psychologie, vol. 18, pp. 65-67.

Kyriazos, T. A., Stalikas, A., Prassa, K., Galanakis, M., Flora, K. \& Chatzilia, V. (2018). The Flow Short Scale (FSS) Dimensionality and What MIMIC Shows on Heterogeneity and Invariance. Psychology, 9(6), pp. 1357-1382. https://doi.org/10.4236/psych.2018.96083.

Lee, M. Y. \& Edmondson, A. C. (2017). Self-managing organizations: Exploring the limits of less-hierarchical organizing. Research in Organizational Behavior, vol. 37, pp. 35-58. https://doi.org/10.1016/j.riob.2017.10.002.

Mathisen, G. E. \& Einarsen, S. (2004). A Review of Instruments Assessing Creative and Innovative Environments Within Organizations. Creativity Research Journal, 16(1), pp. 119-140. https://doi.org/10.1207/s15326934crj1601_12.

Newman, A., Round, H., Wang, S. \& Mount, M. (2020). Innovation climate: A systematic review of the literature and agenda for future research. Journal of Occupational and Organizational Psychology, 93(1), pp. 73-109. https://doi.org/10.1111/joop.12283. 
Newton, P. E., \& Shaw, S. D. (2013). Standards for talking and thinking about validity. Psychological Methods, 18(3), 301-319. https://doi.org/10.1037/a0032969

Ramírez Heller, B., Berger, R. \& Brodbeck, F. C. (2014). Does an Adequate Team Climate for Learning Predict Team Effectiveness and Innovation Potential? A Psychometric Validation of the Team Climate Questionnaire for Learning in an Organizational Context. Procedia - Social and Behavioral Sciences, 114, pp. 543-550. https://doi.org/10.1016/j.sbspro.2013.12.744.

Rheinberg, F., Vollmeyer, R. \& Engeser, S. (2019). FKS - Flow-Kurzskala. https://doi.org/10.23668/PSYCHARCHIVES.2667.

Schutte, N. S. \& Malouff, J. M. (2020). Connections between curiosity, flow and creativity. $\begin{array}{llll}\text { Personality and Individual Differences, } & 152, & 109555 .\end{array}$ https://doi.org/10.1016/j.paid.2019.109555.

Thorgren, S. \& Caiman, E. (2019). The Role of Psychological Safety in Implementing Agile Methods across Cultures. Research-Technology Management, 62(2), pp. 31-39. https://doi.org/10.1080/08956308.2019.1563436.

West, M.A. (1990). Innovation at work. In M.A. West and J.L. Farr (Eds), Innovation and creativity at work: Psychological and organizational strategies, pp. 3-13. Chichester, England: Wiley.

Yongping Xie, Wei Xue, Ling Li, Anmin Wang, Yong Chen, Qianlin Zheng, Yayun Wang, \& Xinjuan Li (2018). Leadership style and innovation atmosphere in enterprises: An empirical study. Technological Forecasting and Social Change, 135, pp. 257-265. https://doi.org/10.1016/j.techfore.2018.05.017 